\title{
Students' Perceptions of the Effectiveness of Using Smartphone Applications in Enhancing Vocabulary Acquisition
}

\author{
Bakr Bagash Mansour Ahmed Al-Sofi ${ }^{1}$ \\ ${ }^{1}$ Department of English, College of Sciences and Arts, Al-Namas, University of Bisha, Kingdom of Saudi Arabia \\ Correspondence: Bakr Bagash Mansour Ahmed Al-Sofi, Assistant Professor, Department of English, College of \\ Sciences and Arts, Al-Namas, University of Bisha, Saudi Arabia. E-mail: bbmansour@ub.edu.sa
}

Received: September 26, 2020

Accepted: November 4, 2020

Online Published: November 17, 2020

doi:10.5539/ijel.v11n1p110

URL: https://doi.org/10.5539/ijel.v11n1p110

\begin{abstract}
The normalization of mobile technology has given rise to mobile devices that are increasingly becoming effective learning platforms. This study explores Saudi learners' perceptions about the application and effectiveness of smartphone applications (apps) in enhancing their vocabulary acquisition. It also examines the factors that might affect their perceptions of smartphone apps' potential role in vocabulary building. An online questionnaire and the researcher's observation were employed to elicit the data from 270 English majoring students at the University of Bisha, Saudi Arabia. SPSS and NVivo software programs were used to analyze the data. The overall findings revealed that respondents have positive perceptions of the effectiveness of smartphone apps in advancing vocabulary acquisition as they have a transformational role in providing them exposure to sufficient vocabulary input. It was also found that the two factors of familiarity with the apps' use and age affected respondents' perceptions of the apps effective role in vocabulary acquisition. Other factors of gender, possessing smartphones, college, educational level, frequency of using the smartphone apps, and the hours spent surfing the apps did not affect respondents' perceptions of the apps effective role in vocabulary acquisition. Hence, it is recommended that teachers and educational policymakers should encourage students to use their free time in accessing smartphone apps to enhance their vocabulary. Program designers should also consider users' learning needs.
\end{abstract}

Keywords: smartphone apps, vocabulary acquisition, perception, effectiveness, Saudi EFL learners, MALL

\section{Introduction}

Mobile devices have increasingly become effective learning platforms. Sandberg et al. (2011) pointed out that "learning in informal contexts is just as important as learning in the context of formal education" (p. 1336). In turn, smartphone applications (apps) play a crucial role in language learning and vocabulary acquisition. However, they were considered in this study as they have complemented intentional learning that has happened in the classroom. They have reinforced limited-time in-class activities by allowing students to review what had been explained and practiced in class in a more pleasant and free environment. Rather than focusing on integrating smartphone apps into the classroom, which could be considered a distraction, this study concentrated on incidental vocabulary learning that has happened in a natural environment without explicit instruction and specific focus of attention.

Similarly, vocabulary is one of the most important aspects of language learning. It plays a significant role in the formation of language. The more words you know, the more you will master the language and communicate successfully. Hence, to help in addressing such importance, it is expected that smartphone apps can make a difference in vocabulary building.

In the context of this study, it is observed that some learners have had a lack of vocabulary knowledge in which they could not convey their intended message successfully when communicating with others. Moreover, many learners of English as a Foreign Language (EFL) may not have the chance to practice the language authentically with native speakers. Hence, smartphone apps are expected to bridge this gap by supplying users with new vocabulary and play a crucial role in facilitating communication in virtual contexts. Moreover, despite the normalization of smartphone apps and their role in vocabulary acquisition, the use of these already existing apps for learning purposes is still open to research (Rahimi \& Miri, 2014), mainly when learners use them in their free time beyond the classroom.

Students can increase their vocabulary knowledge intentionally in the classroom and incidentally outside the class 
activities. Therefore, this study aimed to explore the role of smartphone apps as an important source of input in enhancing learners' vocabulary acquisition incidentally outside the classroom context. Specifically, it concentrated on vocabulary aspects such as meaning, pronunciation, spelling, parts of speech, collocation, synonyms, and antonyms. Additionally, it aimed to identify the factors that might affect learners' perceptions towards such an essential role of the apps on vocabulary building. What drew the researcher's attention was the vocabulary periphery position and the ever-increasing use of these devices anywhere and anytime, especially after the shift from face-to-face to online learning, in educational institutions worldwide, followed by the Covid-19 pandemic outbreak.

This study sounded significant as it responded to the ever-increasing interest among the growing number of smartphone users. It dealt with an up-to-date issue that directly touches the daily lives of learners. In other words, it contributed to the existing knowledge by shedding more light on the effective role of smartphone apps for more incidental vocabulary acquisition outside the classroom from the Saudi EFL learners' perspective. Second, due to the Covid-19 lockdown, it employed an on-the-spot online questionnaire rather than a pre-and post-test questionnaire that is used in the classrooms. Third, it employed the different phonological, morphological, and contextual aspects of vocabulary. Last, the participants were males and females from the different campuses of the University of Bisha, Saudi Arabia.

\section{Review of the Literature}

The essential role of technological devices in our daily life is undeniable; they have played a transformational role. They have accompanied us anytime and anywhere for performing various processes. Mobile technology is not an exception that gives rise to mobile devices such as smartphones, tablets, and iPods that are increasingly normalized and have become an integral part of human life. These devices can also offer learning opportunities that are: spontaneous, informal, contextual, portable, ubiquitous, pervasive, and personal (Kukulska-Hulme et al., 2011). Specifically, the current population has become reliant on smartphones not only as an effective means of communication but also as educational ones. These handheld devices have extended learning opportunities and have maximized exposure to language learning and vocabulary acquisition.

Recently with the rapid spread of the Coronavirus (Covid-19) pandemic, smartphone apps (Blackboard, Zoom, Moodle, Cisco Webex Meetings, WhatsApp, and MOOC) are widely employed for distance learning worldwide. Basal et al. (2016) stated that mobile learning tools have advantageous value for learners compared to other conventional ways of learning. They reported that "using the smartphone applications that are already well-functioning and popular among users could facilitate the mobile learning practices considerably" (p. 50). Pilar et al. (2013) emphasized that "a large amount of applications for mobile phones, tablets, and i-pod players has already been widely employed in EFL" (p. 1189). Specifically, Rahimi and Miri (2014) pointed out that the "swift development of mobile phones in the last decade from simple phones to smartphones ... has made mobile phones efficient learning tools" (p. 1470). Steel (2012) reported that "mobile apps offer a wide range of learning tools [to students] that can be downloaded to their mobile devices and used productively at opportune times in a variety of settings and on-the-go" (p. 1). The effective role of smartphone apps has been greatly emphasized in which learning has become more effective and fruitful when linked with learners' interests and created new study opportunities.

\subsection{The Importance of Vocabulary Acquisition}

Along with the four language skills (listening, speaking, reading, and writing), vocabulary is a prerequisite and a worthy determinant of language proficiency. The more words you know, the more you will master the language and communicate successfully. In line with Nation (1994), Hedge (2000) acknowledged that mastery of vocabulary knowledge determines the mastery of the four language skills. Regarding the vocabulary aspects, Wallace (1989) revealed that to master vocabulary, students should understand word meaning, word use, word grammar, collocation, formality, spelling, and pronunciation. Similarly, Hai-peng and Li-jing (2007) clarified that "without adequate vocabulary knowledge, a second language learner's conversational fluency and reading comprehension will meet difficulties" (p. 55). It strongly confirms the importance of acquiring more vocabulary for mastering the language and hence conveying the intended message.

\subsection{Mobile Technology and Vocabulary Acquisition}

Recently, mobile technology has created great opportunities to shift from a traditional academic environment to mobile learning. Elammari and Cavus (2019) stated that "every individual owns at least one mobile phone, while some individuals even purchase more than one smartphone" (p. 112). Hence, along with the classroom input, the widespread use of smartphones, the most popular among other mobile devices, has revolutionized the way students learn and use the language. They have considerably maximized out-of-class exposure to a massive amount of new 
vocabulary that is required to perform various online tasks and, at the same time, gain new vocabulary. Specifically, numerous language-specific apps have had a constant connection with the target language like online and offline dictionaries, Blackboard, Moodle, Phrasal verbs, Prepositions lite, English tenses, Web-based language learning, and YouTube. Moreover, many other social networking apps such as Facebook, Twitter, WhatsApp, Instagram, Snapchat have had a significant role in users' vocabulary building by chatting and using limitless educational groups and sites that are created for educational purposes. Some of these apps have combined several features in which users could use multiple functions in integrated and seamless ways. Mobile dictionaries, for example, are equipped with audio files in both British and American accents of a given word in which language learners can listen to and then imitate the pronunciation. They also have included various vocabulary aspects such as definition, synonym, antonym, part of speech, and using it in a specific context. When learners come across unknown words, they can figure out the contextual meaning or use such dictionaries to identify their meanings, examine pronunciations, and listen to the sounds in conventional English.

\subsection{Previous Studies}

Recent studies investigated the effective role of smartphone apps in language development, including vocabulary acquisition. For example, Çelik and Yavuz (2017) studied the effectiveness of mobile apps in vocabulary instruction, both contextual and literal. The results showed that mobile apps are effective in language learning. Similarly, Yaman et al. (2015) and Hossain and Ahmed (2016) found that smartphones are used for language learning actively. Hwang and $\mathrm{Wu}(2014)$ investigated the applications and impacts of mobile technology-enhanced learning. The results reported that mobile learning is promising in improving students' learning achievements, motivations, and interests and that smartphones and tablet PCs have gradually become widely adopted mobile learning devices. Hwang and $\mathrm{Fu}(2019)$ reviewed 93 papers in which most studies agreed that there is potential effectiveness in the use of mobile apps for boosting language skills, including vocabulary acquisition. Similarly, Mahdi (2018) conducted a meta-analysis study to identify the effectiveness of using mobile devices on vocabulary learning. He found that mobile devices have a moderate effect on almost all aspects of vocabulary learning. In the same way, Klímová (2018) reviewed 15 original articles and concluded that mobile apps effectively enrich all skills, particularly in retaining new vocabulary, students' perceptions towards using mobile technologies for language learning are positive, and that students using mobile technologies for language learning are more motivated to learn both inside and outside the classroom. Han and Gürlüyer (2017) studied the effects of using smartphones on EFL vocabulary. The study revealed that the use of smartphones could help to learn L2 vocabulary.

Khabsarian-Dehkordi and Ameri-Golestan (2016) examined how mobile learning influences both the acquisition and retention of vocabulary. The results showed that those who used mobile phones or tablet PCs with a social networking application Line were significantly better. Heil et al. (2016) pointed out that most of the mobile apps focus on vocabulary learning in which (84\%) of 50 evaluated apps concentrated on practicing vocabulary items as isolated units and 53\% assessed vocabulary in context, which is important for enhancing students' vocabulary knowledge through incidental repeated exposure to new words. Likewise, Wu (2014) investigated smartphones' effectiveness in helping ESL college students learn English vocabulary. The results reported that smartphones are a very effective method of building vocabulary for Chinese university EFL students. Fageeh (2013) conducted a study among undergraduate Saudi EFL learners to explore mobile phone applications' benefits concerning their potential for improving vocabulary learning and motivation. The results showed that these apps enhanced vocabulary learning.

Specifically, Ajisoko (2020) explored the use of the Duolingo app in improving university student's vocabulary. The results of the study revealed that learners' vocabulary had been improved as they obtained significant post-test scores. Annamalai (2019) investigated the use of the WhatsApp group as a platform for extending learning in a blended learning classroom with a small group of undergraduates in the Malaysian context. Findings reported that the majority of the students expressed the preference for WhatsApp in their reflections despite the problems they face. Likewise, Lawrence (2014) used the WhatsApp group to introduce vocabulary items before reading texts to a group of five undergraduate learners of Afrikaans. It was concluded that WhatsApp is an effective tool for providing outside-the-classroom opportunities to practice vocabulary, especially for weak students.

Kabooha and Elyas (2018) studied the effects of YouTube videos on student vocabulary achievement. The results showed that students considered these useful tools for learning vocabulary and perceived the platform to be easy to use. Zhang (2016) investigated the effect of the English Fun Dubbing (EFD) app on language learning. It was found that the app supported the students' language learning autonomy by providing them with an opportunity to practice the language anywhere. Rahimi and Miri (2014) studied the impact of EFL learners' mobile dictionary use on language learning. The results showed that learners who used the mobile dictionary for learning English improved their language ability more than those who used the printed dictionary. It underscored the vital role 
mobile phones play in extending learning incidentally anywhere and anytime. Similarly, Deng and Shao (2011) examined Chinese university students' attitudes towards the use of a freely available mobile-phone-based e-dictionary app (Remword) for self-directed L2 English vocabulary acquisition. The results indicated that students were ready for mobile learning and were able to well automated their vocabulary learning with this app in their daily life.

Başoğlu and Akdemir (2010) studied the effectiveness of a flashcard app (ECTACO) on L2 Turkish university students' English vocabulary acquisition. Post-testing confirmed that using the flashcards on mobile phones effectively improved students' vocabulary learning than using flashcards on paper. Mobile users also reported that learning English vocabulary in this way is effective and entertaining. Choi and Jeong (2010) examined the effects of using mobile Long Message Service (LMS) lessons on L2 English vocabulary learning among Korean college students. The results reported that using LMS lessons was more effective than using paper materials for vocabulary learning, but there were no significant differences in performance between interactive versus non-interactive LMS.

In light of the studies mentioned above, it was clear that smartphone apps have a beneficial role in language learning, including vocabulary acquisition. They are effective platforms that maximize exposure to a wide range of vocabulary. Moreover, making good use of such apps has triggered and led to users' autonomy that complements intentional learning.

\section{The Study}

\subsection{Objectives and Design of the Study}

This study aimed to explore the effectiveness of smartphone apps in boosting Saudi EFL learners' vocabulary acquisition incidentally outside the classroom. It also identified the factors that might play a role in learners' perceptions regarding the effectiveness of smartphone apps on vocabulary acquisition. The quantitative approach was employed to achieve these research objectives. The data were collected using the online questionnaire and a test at the end of the questionnaire. The researcher's observation was also employed as he was in frequent contact with the students due to his academic and administrative job at the university. This study focused on the research-based vocabulary learning strategies, including dictionary use, morphological analysis (i.e., learning word meanings by analyzing the componential word parts), and contextual analysis (i.e., learning word meanings by referring to learning context).

\subsection{Hypotheses of the Study}

It has been hypothesized that smartphone apps have had an effective role in boosting students' vocabulary acquisition. They have created a space and increased the contextual opportunities for learners by providing them exposure to a wide range of vocabulary while performing various tasks and processes. It has also been expected that factors might affect learners' perceptions regarding the effective use of such apps on L2 vocabulary building. These hypotheses were formulated based on the previous research, and the researcher focused on applying it to the Saudi context.

\subsection{Research Problem and Rationale}

Limited vocabulary in an L2 is a challenge that has impeded successful communication. Learners, as smartphone users, might come across unknown vocabulary when performing the intended processes. Due to vocabulary deficiency, it was observed that students could not convey their ideas and opinions successfully using an L2. They resorted to using their L1 (Arabic) as a kind of code-mixing strategy to explain the intended message and rely on non-verbal skills for communication. Such needs could constitute an inner drive for students to employ smartphone apps positively for L2 vocabulary acquisition. In other words, students are no longer confined to traditional vocabulary memorization. Besides, this study took into account Yang's (2013) and Rahimi and Miri (2014) recommendations that the young field of Mobile Assisted Language Learning (MALL) needs more exploration and is still open to research. Moreover, most smartphone apps are installed in English, and users are pushed to use them and hence acquire new vocabulary. Thus, this issue is worth studying to gain a deeper understanding of smartphone apps' potential effectiveness in enriching students' vocabulary development in the Saudi context with the concerned respondents described as 'Internet generation'.

The present study addressed the following questions:

1) What are the students' perceptions of smartphone apps' overall potential effectiveness in enhancing their vocabulary acquisition?

2) What are the key factors which might affect learners' perceptions about the role of smartphone apps in vocabulary acquisition? 


\subsection{Characteristics of the Participants}

The present study was directed towards the Saudi students majoring in English in the branches of (Bisha, Balqarn, and Al-Namas) at the University of Bisha during the second semester of the academic year 2019/2020. It denotes that the population was homogenous regarding the context, the linguistic and cultural background, the major, the university, and the possession of smartphones. Hence, they were sampled randomly and had the same opportunity of participation and the same standardized questions. The Admission and Registration Deanship reported that the number of students in English departments was $(\mathrm{N}=1716)$, which denoted that the sample $(\mathrm{n}=270)$ was representative.

Table 1. Distribution of English majoring students at the branches of University of Bisha

\begin{tabular}{llll}
\hline College & Gender & No. of students & Percentage \\
\hline College of Arts in Bisha & Males & 154 & $8.97 \%$ \\
& Females & 469 & $27.3 \%$ \\
College of Sciences and Arts in Balqarn & Males & 249 & $14.5 \%$ \\
& Females & 330 & $19.2 \%$ \\
College of Sciences and Arts in Al-Namas & Males & 158 & $9.29 \%$ \\
& Females & 356 & $20.74 \%$ \\
Total & & $\mathbf{1 7 1 6}$ & $\mathbf{1 0 0 \%}$ \\
\hline
\end{tabular}

As vocabulary usually develops with the advance of time, it was found that more than half of the respondents $(\mathrm{n}=$ $181,67.0 \%)$ fell within the second group of age (21-23), followed by the third group (24-26) with ( $\mathrm{n}=47,17.4 \%)$ and the least respondents fell within the fourth group (27-29) with $(\mathrm{n}=3,1.1 \%)$.

In case of the gender variable, the highest percentage $(n=173,64.1 \%)$ was males while $(n=97,35.9 \%)$ was females. As the data were collected from three colleges, more than half of the respondents $(n=155,57.4 \%)$ were from the College of Sciences and Arts in Al-Namas, followed by respondents from the College of Arts in Bisha with $(\mathrm{n}=90,33.3 \%)$. Concerning the education level, it is noteworthy that each semester in Saudi Arabian higher education is considered a level, so students who are enrolled in the English department study eight semesters that are regarded as eight levels. In the case of this study, less than half of the respondents $(n=126,46.7 \%)$ were enrolled in level 8 , which meant that they were graduate students, followed by $(\mathrm{n}=42,15.6 \%)$ from level 6 , and ( $\mathrm{n}$ $=41,15.2 \%$ ) from level 7. Others were distributed among other levels (see Table 2).

In terms of the possession of smartphones, nearly all respondents possessed smartphones $(n=268,99.3 \%)$. Concerning the availability of Internet access on the respondents' smartphones, most of the respondents $(\mathrm{n}=243$, $90.0 \%)$ declared that they had Internet access on their smartphones and $(n=254,94.1 \%)$ were familiar with the use of smartphone apps.

Concerning the frequent use of smartphone apps, around half of the respondents $(n=132,48.9 \%)$ always used the smartphone apps, followed by $(n=97,35.9 \%)$ who often used the smartphone apps. Specifically, the respondents spent many hours using smartphone apps ranging from 3-4 hours a day $(\mathrm{n}=90,33.3 \%)$ followed by 5-6 hours a day $(\mathrm{n}=64,23.7 \%)$. 
Table 2. Descriptive statistics of the respondents' general information

\begin{tabular}{|c|c|c|c|}
\hline Section 1: General information & Options & Frequency & Percentage \\
\hline \multirow[t]{4}{*}{ Age } & Group 1: 18-20 & 39 & $14.4 \%$ \\
\hline & Group 2: $21-23$ & 181 & $67.0 \%$ \\
\hline & Group 3: 24-26 & 47 & $17.4 \%$ \\
\hline & Group 4: 27-29 & 3 & $1.1 \%$ \\
\hline \multirow[t]{2}{*}{ Gender } & Male & 173 & $64.1 \%$ \\
\hline & Female & 97 & $35.9 \%$ \\
\hline \multirow[t]{3}{*}{ College } & College of Arts in Bisha & 90 & $33.3 \%$ \\
\hline & College of Sciences and Arts in Al-Namas & 155 & $57.4 \%$ \\
\hline & College of Sciences and Arts in Balqarn & 25 & $9.3 \%$ \\
\hline \multirow[t]{8}{*}{ Education level } & Level 1 & 11 & $4.1 \%$ \\
\hline & Level 2 & 21 & $7.8 \%$ \\
\hline & Level 3 & 3 & $1.1 \%$ \\
\hline & Level 4 & 20 & $7.4 \%$ \\
\hline & Level 5 & 6 & $2.2 \%$ \\
\hline & Level 6 & 42 & $15.6 \%$ \\
\hline & Level 7 & 41 & $15.2 \%$ \\
\hline & Level 8 & 126 & $46.7 \%$ \\
\hline \multirow[t]{2}{*}{ Do you have a smartphone? } & Yes & 268 & $99.3 \%$ \\
\hline & No & 2 & $.7 \%$ \\
\hline \multirow[t]{2}{*}{ Do you have Internet access on your smartphone? } & Yes & 243 & $90.0 \%$ \\
\hline & No & 27 & $10.0 \%$ \\
\hline \multirow{2}{*}{$\begin{array}{l}\text { Are you familiar with the use of diverse } \\
\text { smartphone apps? }\end{array}$} & Yes & 254 & $94.1 \%$ \\
\hline & No & 16 & $5.9 \%$ \\
\hline \multirow[t]{5}{*}{ How often do you use smartphone apps? } & Always & 132 & $48.9 \%$ \\
\hline & Often & 97 & $35.9 \%$ \\
\hline & Sometimes & 36 & $13.3 \%$ \\
\hline & Seldom & 4 & $1.5 \%$ \\
\hline & Never & 1 & $.4 \%$ \\
\hline \multirow{5}{*}{$\begin{array}{l}\text { How many hours do you spend using smartphone } \\
\text { apps? }\end{array}$} & $1-2$ hours a day & 39 & $14.4 \%$ \\
\hline & $3-4$ hours a day & 90 & $33.3 \%$ \\
\hline & $5-6$ hours a day & 64 & $23.7 \%$ \\
\hline & $7-8$ hours a day & 39 & $14.4 \%$ \\
\hline & more than 8 hours a day & 38 & $14.1 \%$ \\
\hline
\end{tabular}

\subsection{Research Instruments}

The data were collected using an online questionnaire and the researcher's observation. The first was used as the main instrument and the latter as a complementary one to gain deeper insights on the topic under study. First, the questionnaire items were carefully designed, taking into account clarity, and achieving the objectives of the study. It began with an introductory paragraph that introduced the objectives of the study, ensured anonymity and confidentiality, and clarified the way to respond to the items. A five-item Likert-type scale was used with scores ranging from strongly agree (5), which denoted a highly positive perception, to strongly disagree (1), which represented extremely negative perception. The questionnaire was composed of two sections: general information and uses of smartphone apps for L2 vocabulary acquisition. The first section considered the respondents' general characteristics such as age, gender, education level, possessing smartphones, access to the Internet, familiarity with the smartphone apps, and frequency of the use of apps. Such items identified the statistically significant differences in using smartphone apps and the acquisition of new English vocabulary.

The second section explored participants' perceptions of smartphone apps' potential role in their vocabulary acquisition (18 items). Vocabulary is a multi-dimensional term that includes various aspects. Hence, the items of the main scale were mainly based on several vocabulary aspects, including dictionary use (spelling, unknown words, word classes), morphological analysis (i.e., learning word meanings by analyzing the componential word parts and formation, collocations, synonyms, or antonyms), and contextual analysis (i.e., learning word meanings by referring to the learning context, guessing depending on contextual clues). The questionnaire ended up with an open-ended question asking the respondents to write down examples of the vocabulary they acquired due to the apps use. This question played the role of a vocabulary test that lets students recall and write down the new words they have acquired because of using their smartphone apps. It also increased the validity of the study. 


\subsection{Validity and Reliability of the Research Instrument}

The questionnaire was carefully designed to ascertain the validity of the instrument. It was sent to a group of academicians on the ResearchGate, a virtual academic platform. It was approved with some suggestions and modifications before circulating the final version of the questionnaire. Moreover, to minimize misunderstanding and obtain good-quality data, the items were written in simple English and translated into Arabic. Such procedures could ensure that the instrument has measured the intended objectives, and foreseeable researchers could replicate it.

Then, the questionnaire was piloted to 16 students selected randomly from different colleges and then excluded from the target sample. Cronbach Alpha was found very reliable $(p=.946)$. The final version of the questionnaire was disseminated to the students, and the reliability analysis of the 18 items was found very reliable $(\mathrm{p}=.944)$ too.

Table 3. Reliability analysis using Cronbach's Alpha coefficient

\begin{tabular}{llll}
\hline & No. of respondents & Cronbach's Alpha & No. of items \\
\hline With the pilot group & 16 & .946 & 18 \\
The final version of the instrument & 270 & .944 & 18 \\
\hline
\end{tabular}

Additionally, the Spearman correlation was conducted to explore the strength and direction of the linear relationship between the variables. The results in Table 4 indicated that the items and their specified scales were positively correlated at $(\mathrm{p}=.000)$ in which the strong positive correlation was $(\mathrm{r}=.698)$, and the medium correlation was $(\mathrm{r}=.350)$. Interestingly, there was no small correlation between the items. To sum up, it can be reported that the questionnaire was highly reliable in which the items of the scales were positively correlated, and the internal consistency was achieved. Therefore, the instrument met the objectives of the study and could be replicated in other contexts.

Table 4. Spearman correlation and sig. (2-tailed) of section 2 (18 items)

\begin{tabular}{|c|c|c|}
\hline $\begin{array}{l}\text { I think that the smartphone apps (Google, Facebook, Twitter, Snapchat, Instagram, } \\
\text { YouTube, WhatsApp, English dictionaries, Translator, etc.) help me to ... }\end{array}$ & Spearman correlation & Sig. (2-tailed) \\
\hline acquire new English vocabulary & $.499 * *$ & .000 \\
\hline know the meaning of new English vocabulary. & $.487 * *$ & .000 \\
\hline know the meaning of new English expressions. & $.535 * *$ & .000 \\
\hline identify the meaning of the new English vocabulary through the context. & $.597 * *$ & .000 \\
\hline identify the exact meaning of the new vocabulary. & $.585 * *$ & .000 \\
\hline remember the meaning of the acquired vocabulary later on. & $.557 * *$ & .000 \\
\hline use this new vocabulary later in my daily life. & $.616^{* *}$ & .000 \\
\hline write the English vocabulary correctly. & $.633 * *$ & .000 \\
\hline remember the correct pronunciation of the new English vocabulary. & $.609 * *$ & .000 \\
\hline reinforce the existing English vocabulary. & $.639 * *$ & .000 \\
\hline link the new vocabulary to their meanings in the Arabic language. & $.630 * *$ & .000 \\
\hline identify the word class of the new English vocabulary. & $.647 * *$ & .000 \\
\hline know the collocation of the new English vocabulary. & $.680 * *$ & .000 \\
\hline connect the new vocabulary to their synonyms. & $.698 * *$ & .000 \\
\hline connect the new vocabulary to their antonyms. & $.667 * *$ & .000 \\
\hline keep a vocabulary notebook. & $.633 * *$ & .000 \\
\hline ask other people (friends, mates) about the meaning of the new vocabulary. & $.604 * *$ & .000 \\
\hline skip the new vocabulary and carry on using smartphone apps. & $.578 * *$ & .000 \\
\hline
\end{tabular}

Note. $* *$. Correlation is significant at the 0.01 level (2-tailed).

Second, the researcher's observation was used as a complementary data collection instrument as he has been in daily contact with the students because he has been the academic registrar, the academic counselor, and a member of many committees.

\subsection{Data Collection and Analysis Procedures}

The Vice Rector for Graduate Studies and Scientific Research approved the questionnaire through written informed consent. For easy dissemination, the questionnaire was formulated through Google forms, and the hyperlink and the generated QR Code were widely circulated on the students' blackboard and WhatsApp groups. 
With the help of the researcher's colleagues, the data were collected from the target population during the second semester of the academic year 2019/2020. The data collection process lasted for one month and stopped for the data analysis to start. Once the data gathering stopped, the data were exported from Google forms into an Excel spreadsheet and then into the SPSS program. Regarding the observation, the researcher recorded how the students use smartphone apps by asking them some informal questions about the types of uses and benefits of smartphone apps and whether they acquire new vocabulary when using such apps or not. Using the SPSS software program (version 25), the suitable descriptive and inferential statistical techniques were run to meet the objectives of the study. As the population was homogeneous, the sample size was big $(\mathrm{n}=270)$, and the data were collected randomly, the parametric techniques were run to identify the statistically significant differences between the different groups. On the one hand, the t-test was used with the independent categorical variables of two groups (gender, possessing smartphones, Internet access, and familiarity with the smartphone apps) to compare their scores with a total of the 18-item scale of vocabulary aspects (continuous dependent variable). On the other hand, ANOVA was applied with the independent variables of more than two groups (age, college, education level, frequency of using the smartphone apps, and the hours spent surfing the apps) to compare their scores with the total of the 18-item scale of vocabulary aspects. Additionally, the NVivo software program (version 12) was run to analyze the data of the open question that testified students' acquired vocabulary.

\section{Results of the Study}

\subsection{Results of the Questionnaire}

The results in Table 5 revealed that the general item of the study (I think that the smartphone apps help me to acquire new English vocabulary) got the highest rank $(\mathrm{M}=4.54, \mathrm{SD}=.648)$. It was followed by the second item ( $I$ think that the smartphone apps help me to know the meaning of new English vocabulary) with $(\mathrm{M}=4.51, \mathrm{SD}$ $=.688$ ). Similarly, item 11 (I think that the smartphone apps help me to link the new vocabulary to their meanings in the Arabic language $)$ got the third rank $(\mathrm{M}=4.38, \mathrm{SD}=.775)$. On the other hand, the lowest rank was given to item 12 (I think that the smartphone apps help me to identify the word class of the new English vocabulary) with $(\mathrm{M}=4.05, \mathrm{SD}=.955)$. It was found that the use of smartphone apps was not helpful in morphological analysis, specifically in identifying the word classes. Generally, the weighted average of the main scale (smartphone apps uses in gaining vocabulary) was $(\mathrm{M}=4.2619, \mathrm{SD}=.60629)$, which proved that the scale average was (strongly agree) attitude according to the 5-point Likert interval. 
Table 5. Descriptive statistics of the smartphone apps use for vocabulary acquisition scale (18 items)

\begin{tabular}{|c|c|c|c|c|c|c|c|c|c|}
\hline \multicolumn{2}{|c|}{$\begin{array}{l}\text { I think that smartphone apps help me } \\
\text { to ... }\end{array}$} & \multirow{2}{*}{$\begin{array}{l}\begin{array}{l}\text { strongly } \\
\text { agree }\end{array} \\
165\end{array}$} & \multirow{2}{*}{$\begin{array}{l}\text { agree } \\
90\end{array}$} & \multirow{2}{*}{$\begin{array}{l}\text { uncertain } \\
11\end{array}$} & \multirow{2}{*}{$\begin{array}{l}\text { disagree } \\
4\end{array}$} & \multirow{2}{*}{\begin{tabular}{|l|}
$\begin{array}{l}\text { strongly } \\
\text { disagree }\end{array}$ \\
0
\end{tabular}} & \multirow{2}{*}{$\begin{array}{l}\text { Mean } \\
4.54\end{array}$} & \multirow{2}{*}{$\begin{array}{l}\begin{array}{l}\text { Std. } \\
\text { Deviation }\end{array} \\
.648\end{array}$} & \multirow{2}{*}{$\begin{array}{l}\text { Rank } \\
1\end{array}$} \\
\hline acquire new English vocabulary. & $\mathrm{N}$ & & & & & & & & \\
\hline & $\%$ & 61.1 & 33.3 & 4.1 & 1.5 & 0 & & & \\
\hline know the meaning of new English & $\mathrm{N}$ & 165 & 83 & 18 & 4 & 0 & 4.51 & 688 & 2 \\
\hline vocabulary. & $\%$ & 61.1 & 30.7 & 6.7 & 1.5 & 0 & & & \\
\hline know the meaning of new English & $\mathrm{N}$ & 139 & 95 & 28 & 7 & 1 & 4.35 & .798 & 5 \\
\hline expressions. & $\%$ & 51.5 & 35.2 & 10.4 & 2.6 & .4 & & & \\
\hline identify the meaning of the new & $\mathrm{N}$ & 137 & 92 & 35 & 5 & 1 & 4.33 & .799 & 6 \\
\hline $\begin{array}{l}\text { English vocabulary through the } \\
\text { context. }\end{array}$ & $\%$ & 50.7 & 34.1 & 13.0 & 1.9 & .4 & & & \\
\hline identify the exact meaning of the & $\mathrm{N}$ & 105 & 100 & 59 & 4 & 2 & 4.12 & .850 & 13 \\
\hline new vocabulary. & $\%$ & 38.9 & 37.0 & 21.9 & 1.5 & .7 & & & \\
\hline remember the meaning of the & $\mathrm{N}$ & 129 & 100 & 34 & 7 & 0 & 4.30 & .787 & 7 \\
\hline acquired vocabulary later on. & $\%$ & 47.8 & 37.0 & 12.6 & 2.6 & 0 & & & \\
\hline use this new vocabulary later in my & $\mathrm{N}$ & 140 & 90 & 31 & 7 & 2 & 4.33 & .835 & 6 \\
\hline daily life. & $\%$ & 51.9 & 33.3 & 11.5 & 2.6 & .7 & & & \\
\hline write the English vocabulary & $\mathrm{N}$ & 125 & 98 & 30 & 11 & 6 & 4.20 & .948 & 10 \\
\hline correctly. & $\%$ & 46.3 & 36.3 & 11.1 & 4.1 & 2.2 & & & \\
\hline remember the correct pronunciation & $\mathrm{N}$ & 130 & 94 & 36 & 8 & 2 & 4.27 & .855 & 8 \\
\hline of the new English vocabulary. & $\%$ & 48.1 & 34.8 & 13.3 & 3.0 & .7 & & & \\
\hline reinforce the existing English & $\mathrm{N}$ & 135 & 107 & 21 & 6 & 1 & 4.37 & .753 & 4 \\
\hline vocabulary. & $\%$ & 50.0 & 39.6 & 7.8 & 2.2 & .4 & & & \\
\hline link the new vocabulary to their & $\mathrm{N}$ & 142 & 96 & 25 & 6 & 1 & 4.38 & .775 & 3 \\
\hline meanings in the Arabic language. & $\%$ & 52.6 & 35.6 & 9.3 & 2.2 & .4 & & & \\
\hline identify the word class of the new & $\mathrm{N}$ & 107 & 89 & 59 & 11 & 4 & 4.05 & .955 & 15 \\
\hline English vocabulary. & $\%$ & 39.6 & 33.0 & 21.9 & 4.1 & 1.5 & & & \\
\hline know the collocation of the new & $\mathrm{N}$ & 108 & 104 & 44 & 10 & 4 & 4.12 & .913 & 13 \\
\hline English vocabulary & $\%$ & 40.0 & 38.5 & 16.3 & 3.7 & 1.5 & & & \\
\hline connect the new vocabulary to their & $\mathrm{N}$ & 113 & 107 & 36 & 14 & 0 & 4.18 & .854 & 11 \\
\hline synonyms. & $\%$ & 41.9 & 39.6 & 13.3 & 5.2 & 0 & & & \\
\hline connect the new vocabulary to their & $\mathrm{N}$ & 123 & 97 & 36 & 13 & 1 & 4.21 & .878 & 9 \\
\hline antonyms. & $\%$ & 45.6 & 35.9 & 13.3 & 4.8 & .4 & & & \\
\hline keep a vocabulary notebook. & $\mathrm{N}$ & 115 & 90 & 47 & 17 & 1 & 4.11 & .936 & 14 \\
\hline & $\%$ & 42.6 & 33.3 & 17.4 & 6.3 & .4 & & & \\
\hline ask other people (friends, mates) & $\mathrm{N}$ & 130 & 88 & 32 & 18 & 2 & 4.21 & .945 & 9 \\
\hline $\begin{array}{l}\text { about the meaning of the new } \\
\text { vocabulary. }\end{array}$ & $\%$ & 48.1 & 32.6 & 11.9 & 6.7 & .7 & & & \\
\hline skip the new vocabulary and carry & $\mathrm{N}$ & 116 & 98 & 37 & 13 & 6 & 4.13 & .973 & 12 \\
\hline on using the smartphone apps & $\%$ & 43.0 & 36.3 & 13.7 & 4.8 & 2.2 & & & \\
\hline Total of the 18 -item scale (smartphon & app & ses in gain & g vocab & & & & 4.2619 & .60629 & \\
\hline
\end{tabular}

Regarding testing the factors that might affect the students' perceptions of the effective role of smartphone apps on vocabulary acquisition, the t-test reported that there were no statistically significant differences in the mean scores of the variables (gender, possessing smartphones and Internet access) as ( $\geq .05$ ) except the familiarity-with-the-apps variable as $(p=.000)$. The statistical difference was in favor of students who were familiar with smartphone apps, which denoted that it affected the respondents' perceptions regarding smartphone effectiveness in acquiring vocabulary.

Table 6. Significant differences of two-group variables using t-test analysis

\begin{tabular}{|c|c|c|c|c|c|c|c|}
\hline $\begin{array}{l}\text { The total of the uses of smartphone apps in } \\
\text { acquiring new English vocabulary/groups }\end{array}$ & groups & $\mathbf{N}$ & $\mathbf{M}$ & SD & $\mathbf{t}$ & $\mathbf{F}$ & $\begin{array}{l}\text { Sig. } \\
\text { (2-tailed) }\end{array}$ \\
\hline \multirow[t]{2}{*}{ Gender } & Male & 173 & 4.24 & .607 & -.867 & .000 & .386 \\
\hline & Female & 97 & 4.30 & .605 & & & \\
\hline \multirow[t]{2}{*}{ Possessing smartphones } & Yes & 268 & 4.27 & .606 & 1.396 & 2.514 & .164 \\
\hline & No & 2 & 3.67 & .157 & & & \\
\hline \multirow[t]{2}{*}{ Internet access } & Yes & 243 & 4.28 & .607 & 1.684 & .101 & .093 \\
\hline & No & 27 & 4.08 & .577 & & & \\
\hline \multirow[t]{2}{*}{ Familiarity with the apps } & Yes & 254 & 4.29 & .591 & 3.007 & & $.003 *$ \\
\hline & No & 16 & 3.83 & .692 & & & \\
\hline
\end{tabular}

Note. *. The mean difference is significant at the 0.05 level. 
On the other hand, ANOVA revealed that there were no statistically significant differences among the mean scores of the different group variables with the total of the uses of smartphone apps in acquiring new English vocabulary as $(p \geq .05)$ except age variable as $(p=.010)$. It means there was a statistically significant difference somewhere among the mean scores of the age groups. Tukey HSD test indicated that the significant difference was in favor of group 4 compared with the age groups 1 and 4 in which $(\mathrm{p}=.032)$ and groups 2 and 4 in which (p $=.014$ ). It indicated that the age variable affected the respondents' perceptions regarding the apps uses for vocabulary building. It should be noted that the non-parametric techniques (Kruskal-Wallis Test and Mann-Whitney U Test) were run, and the same results were obtained.

Table 7. Significant differences of variables with more than two groups using ANOVA analysis

\begin{tabular}{|c|c|c|c|c|c|c|}
\hline \multicolumn{2}{|c|}{$\begin{array}{l}\text { The total of the uses of smartphone apps in acquiring new English } \\
\text { vocabulary/Groups }\end{array}$} & \multirow{2}{*}{$\begin{array}{l}\mathbf{N} \\
39\end{array}$} & \multirow{2}{*}{$\begin{array}{l}\mathbf{M} \\
4.25\end{array}$} & \multirow{2}{*}{$\begin{array}{l}\text { SD } \\
.643\end{array}$} & \multirow{2}{*}{$\begin{array}{l}\text { F } \\
3.863\end{array}$} & \multirow{2}{*}{$\begin{array}{l}\text { Sig. } \\
.010^{*}\end{array}$} \\
\hline Age & Group 1: 18-20 & & & & & \\
\hline & Group 2: 21-23 & 181 & 4.31 & .518 & & \\
\hline & Group 3: 24-26 & 47 & 4.15 & .817 & & \\
\hline & Group 4: 27-29 & 3 & 3.26 & .225 & & \\
\hline \multirow[t]{3}{*}{ College } & College of Arts in Bisha & 90 & 4.309 & 624 & .399 & .671 \\
\hline & College of Sciences and Arts in Al-Namas & 155 & 4.239 & .529 & & \\
\hline & College of Sciences and Arts in Balqarn & 25 & 4.238 & .766 & & \\
\hline \multirow[t]{8}{*}{ Education level } & Level 1 & 11 & 4.450 & 0.388 & .843 & .553 \\
\hline & Level 2 & 21 & 4.206 & 0.612 & & \\
\hline & Level 3 & 3 & 4.500 & 0.500 & & \\
\hline & Level 4 & 20 & 4.025 & 0.734 & & \\
\hline & Level 5 & 6 & 4.472 & 0.469 & & \\
\hline & Level 6 & 42 & 4.324 & 0.515 & & \\
\hline & Level 7 & 41 & 4.263 & 0.491 & & \\
\hline & Level 8 & 126 & 4.256 & 0.666 & & \\
\hline \multirow{5}{*}{$\begin{array}{l}\text { Frequency of using } \\
\text { smartphone apps }\end{array}$} & Always & 132 & 4.352 & 0.537 & 1.867 & .117 \\
\hline & Often & 97 & 4.197 & 0.656 & & \\
\hline & Sometimes & 36 & 4.162 & 0.659 & & \\
\hline & Seldom & 4 & 3.958 & 0.803 & & \\
\hline & Never & 1 & 3.556 & -180 & & \\
\hline \multirow{5}{*}{$\begin{array}{l}\text { The hours spent surfing } \\
\text { the apps }\end{array}$} & $1-2$ hours a day & 39 & 4.118 & 0.576 & 1.359 & .248 \\
\hline & $3-4$ hours a day & 90 & 4.207 & 0.610 & & \\
\hline & $5-6$ hours a day & 64 & 4.309 & 0.671 & & \\
\hline & $7-8$ hours a day & 39 & 4.342 & 0.556 & & \\
\hline & more than 8 hours a day & 38 & 4.379 & 0.547 & & \\
\hline
\end{tabular}

Note. ${ }^{*}$. The mean difference is significant at the 0.05 level.

Regarding the students' responses to the open question, Could you please write down some of the English vocabularies that you have acquired from the smartphone apps? a list of helpful vocabulary related to the frequent use of the apps was written down. The following word frequency query and clouds summarized the distribution of the acquired vocabulary. 
Table 8. Example of the word frequency query results of the open question using NVivo

\begin{tabular}{lll}
\hline Word & Count & Weighted Percentage (\%) \\
\hline thank & 20 & 1.49 \\
vocabulary & 20 & 1.49 \\
words & 20 & 1.49 \\
good & 16 & 1.19 \\
English & 15 & 1.12 \\
phone & 15 & 1.12 \\
apps & 13 & 0.97 \\
learn & 12 & 0.89 \\
smartphone & 12 & 0.89 \\
nothing & 11 & 0.82 \\
many & 10 & 0.75 \\
done & 9 & 0.67 \\
like & 9 & 0.67 \\
add & 8 & 0.60 \\
agree & 8 & 0.60 \\
lot & 8 & 0.60 \\
play & 8 & 0.60 \\
send & 8 & 0.60 \\
thanks & 8 & 0.60 \\
using & 8 & 0.60 \\
download & 7 & 0.52 \\
help & 7 & 0.52 \\
new & 7 & 0.52 \\
recommend & 7 & 0.52 \\
smart & 7 & 0.52 \\
\hline & & \\
\hline
\end{tabular}

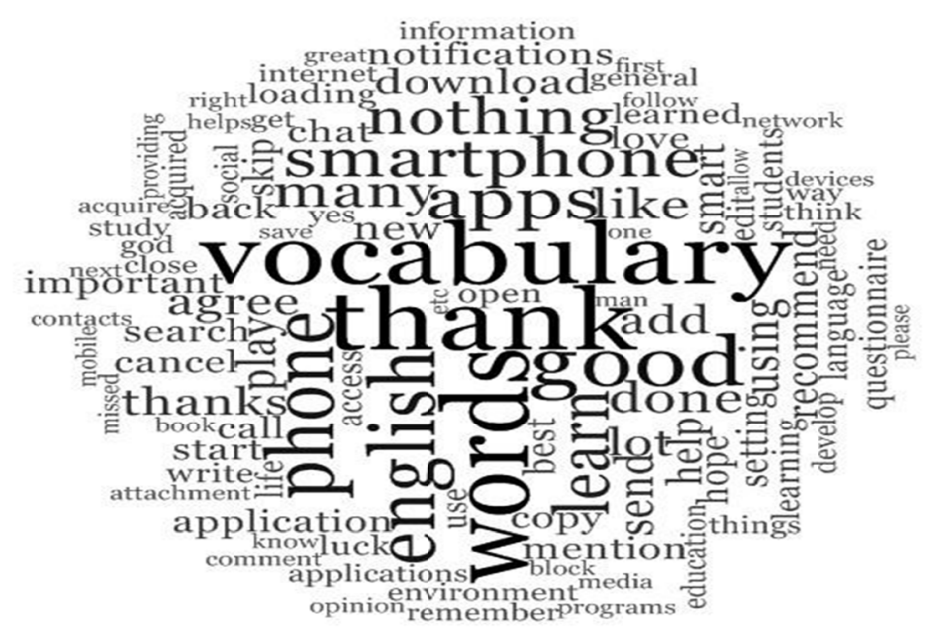

Figure 1 . The acquired vocabulary obtained from the open-ended question

\subsection{The Researcher's Observation}

Through the students' responses to the direct informal questions regarding the benefits of smartphone apps, especially for acquiring new vocabulary, it was noticed that students were inclined to the frequent creative use of their smartphones for performing various academic services online such as adding or dropping courses, dropping semesters, checking their timetables, creating WhatsApp and Telegram groups, downloading courses materials, uploading their assignments, revising lectures, preparing for exams, checking their absence and grades, contacting with their peers and teachers, among others. Recently, because of the Coronavirus (Covid-19) pandemic, students have attended virtual classes regularly, done assignments and sat for tests, and participated in forums and discussion boards online via Blackboard, Zoom, Moodle, and Cisco Webex Meetings. Given that, students came across unknown vocabulary and were enforced to acquire it for better achievements of such processes. In other words, such widespread employment of smartphone apps has played a significant role in performing students' 
academic and administrative tasks and, at the same time, enhancing vocabulary acquisition. From the researcher's viewpoint, it seemed clear that students generally held positive perceptions of the effective role of smartphone apps that cement their vocabulary acquisition. That was also clear in their general responses to some questions related to the uses of smartphone apps. Besides, some acquired vocabulary helped them solve many of the technical problems they faced while using the devices to attend virtual classes.

On the whole, it was obvious that the respondents were highly aware of the beneficial role of smartphone apps in enriching their L2 vocabulary incidentally outside the classroom anywhere anytime. Such apps could also enhance learners' autonomy to get benefits from the various facilities in their spare time. This overall result supported the first hypothesis that smartphone apps play an effective role in boosting students' L2 vocabulary acquisition. Moreover, it was found that only two key factors were statistically significant (familiarity with the apps and age), which affected the respondents' perceptions regarding the effectiveness of the apps in L2 vocabulary acquisition. Other factors were not statistically significant in the given context and among the concerned respondents. It indicated that the second hypothesis, other factors might affect learners' perceptions regarding the use of smartphone apps in L2 vocabulary building, was partially refuted.

\section{Discussion of the Results}

This study examined Saudi EFL learners' perceptions of the potential effectiveness of smartphone apps in enhancing vocabulary acquisition. It also investigated the key factors that might affect learners' perceptions regarding this potential role. The participants were Saudi students majoring in English, University of Bisha. The quantitative approach was used to obtain the data using the questionnaire and the researcher's observation.

Overall, the findings show that the incidental out-of-class use of these apps, as a source of input, enhanced vocabulary acquisition. Such apps accelerate vocabulary acquisition due to their vast use in people's daily lives. In particular, it was found that the main item of the study (I think that the smartphone apps help me to acquire new English vocabulary) got the highest rank. It was evident that smartphone apps have become an important platform for vocabulary acquisition increasingly. It could be deduced that the students were aware of the benefits and effectiveness of smartphone apps regarding vocabulary boosting as such devices accompany them anytime anywhere they go. They were found to be inclined to the use of the apps as they can contextualize the acquired vocabulary in their daily situations. This important finding is in harmony with the findings of the previous studies (Fageeh, 2013; Han \& Gürlüyer, 2017; Heil et al., 2016; Hossain \& Ahmed, 2016; Khabsarian-Dehkordi \& Ameri-Golestan, 2016; Klímová, 2018; Mahdi, 2018; Wu, 2014; Yaman et al., 2015) which generally examined the effectiveness of smartphone apps on vocabulary acquisition in various contexts using different procedures and instruments. They concluded that smartphone apps play an effective role in building learners' vocabulary. In other words, they found that vocabulary acquisition can be significantly enhanced due to the users' effective use of smartphone apps. This study also concludes that smartphone users are more proactive and attentive than reactive or passive recipients. It was elicited that when they come across unknown words, they figure out their meanings to help them perform various processes and, at the same time, use such vocabulary in daily contact.

Interestingly, the bulk of vocabulary written down by the respondents was helpful as it is used in their daily life. It proves the actual effectiveness and the reciprocal relationship between smartphone apps and vocabulary acquisition. It is a practical test that proved that there is no gap between learners' perceptions towards the effectiveness of the apps and their real acquisition of new vocabulary. It should be declared that the findings revealed that the apps are not effective to the expected level regarding the morphological analysis to identify words classes. It can be interpreted with students' unawareness of the different word classes as some of the apps, except the dictionaries, do not refer to word classes. Moreover, they might not need such information for performing their various processes.

After testing the assumed factors that might affect respondents' perceptions regarding the apps effective role in vocabulary acquisition, it was found that only two key factors (familiarity with the apps use and age) affected the students' use of smartphone apps in an L2 vocabulary building. It referred that the second hypothesis, other factors might affect learners' use of smartphone apps in an L2 vocabulary building, was partially refuted. It can be justified as the students who had Internet access on their smartphones had more chances and opportunities to surf the Internet anytime anywhere than those who did not have. Moreover, the more the students used the apps and were familiar with them, the more they acquired new vocabulary. Specifically, smartphones have normalized students' lives as they are handheld devices that are widely used to perform various tasks anytime and anywhere. It is also a result of the recent technological developments that are happening constantly. Moreover, older students are more mature to realize their responsibilities and needs for getting the vocabulary they need than younger ones who are addicted to entertainment apps taking no consideration of the learning purposes. 
Other factors (gender, possessing smartphones, college, education level, frequency of using the smartphone apps, and the hours spent using the apps) did not affect the respondents' perceptions regarding the smartphones' potential role in vocabulary acquisition. It could be traced back to the respondents' homogenous nature regarding the context, linguistic and cultural background, major, university, possessing smartphones, the same opportunity of participation, and the same standardized questions. Specifically, it could be justified as both males and females had the same desire and need to possess and use smartphones all the time. If not all, most of the respondents had smartphones and Internet access due to the widespread use of such handy and cheap devices and Internet packages that can be used in their daily life.

\section{Conclusion}

Vocabulary is central and of prime importance to language learning. It can be acquired incidentally through promising smartphone apps that can make a difference in the learning process. This study investigated Saudi students' perceptions of the effectiveness of smartphone apps in enhancing their vocabulary. It also examined the key factors that might affect students' perceptions regarding such a role. It was hypothesized that smartphone apps have the potential to play an effective role in boosting students' vocabulary. The results showed that the first hypothesis was supported in which students highly appreciated the role of such apps in helping them acquire new vocabulary effortlessly. It provides evidence that students have a growing interest in the apps to support their vocabulary learning. It also proves the reciprocal relationship between smartphone apps and vocabulary acquisition in which students who employ smartphone apps positively get more vocabulary and hence be able to achieve various online processes and use the language efficiently as well. Moreover, these apps provide users with a learner-centered opportunity with ubiquitously accessible and flexible practices. This idea was also demonstrated by the bulk of vocabulary produced by the findings. Moreover, the findings revealed that the second hypothesis was partially refuted in which only the two factors of familiarity with the smartphone apps and age affected students' perceptions regarding the role of smartphone apps in vocabulary building. Other factors did not make sense in the context of this study with the concerned respondents.

\subsection{Implications and Recommendations}

Learners' awareness of the essential role of vocabulary acquisition in language learning and the helpful role of smartphone apps in vocabulary acquisition is crucial. Specifically, being accustomed to the positive use of smartphone apps trains students adequately for the labor market after graduation. As the actual use of smartphone apps for vocabulary acquisition might not be up to the required level, teachers and policymakers should encourage students to maximize the use of such self-led and self-directed apps to best suit their learning needs and personal preferences that reinforce in-class tasks and activities. They should be motivated to keep pace with the latest apps and perceive smartphone devices as not only social and/or entertaining ones but also as complementary learning ones that reinforce their fluency. Designers should also tailor free educationally-based apps considering users' communicatively-authentic needs. Vocabulary knowledge is a demanding process that is gradually developed. After the motivating and promising status of smartphone apps is confirmed, it is expected that employing them for learning purposes will be normalized and be a strategic choice in the learning process.

\subsection{Limitations and Future Research}

The findings of this study can be cautiously generalized beyond the immediate context of the study. Hence, for adequate sample representation, interested researchers could conduct studies with samples from other Saudi universities. Moreover, this study took into consideration vocabulary acquisition; hence, future studies could investigate the use of such acquired vocabulary in authentic contexts. Last, as this study used many smartphone apps, future research could concentrate on the famous learning-tailored ones.

\section{Acknowledgments}

The author is very thankful to the University of Bisha represented by the Vice Rector for Graduate Studies and Scientific Research, Admission and Registration Deanship, and the dean of College of Sciences and Arts in Al-Namas for their constant support and encouragement to conduct this study. Gratitude must also go to the respondents for their invaluable contribution to the study. Sincere gratitude also extends to my dear colleagues for their help in circulating the questionnaire among the students. Thanks must also go to the ResearchGate platform scholars who provided me with their guidance and suggestions that led to the instrument's high reliability. 


\section{References}

Ajisoko, P. (2020). The use of Duolingo apps to improve English vocabulary learning. International Journal of Emerging Technologies in Learning, 15(7), 149-155. https://doi.org/10.3991/ijet.v15i07.13229

Annamalai, N. (2019). Using Whatsapp to extend learning in a blended classroom environment. Teaching English with Technology, 19(1), 3-20. https://files.eric.ed.gov/fulltext/EJ1204549.pdf

Basal, A., Yilmaz, S., Tanriverdi, A., \& Sari, L. (2016). Effectiveness of mobile applications in vocabulary teaching. Contemporary Educational Technology, 7(1), 47-59. https://doi.org/10.30935/cedtech/6162

Başoğlu, E., \& Akdemir, O. (2010). A comparison of undergraduate students' English vocabulary learning: Using mobile phones and flash cards. Turkish Online Journal of Educational Technology, 9(3), 1-7. Retrieved from http://www.tojet.net

Çelik, Ö., \& Yavuz, F. (2017). The effect of using mobile applications on literal and contextual vocabulary instruction. International Journal of Learning and Teaching, 10(2), 126-136. https://doi.org/10.18844/ijlt.v10i2.3407

Choi, E. J., \& Jeong, D. B. (2010). The effects of college students' vocabulary learning by using mobile LMS lessons. Multimedia-Assisted Language Learning, 13(3), 279-302. Retrieved from http://www.dbpia.co.kr

Deng, H., \& Shao, Y. (2011). Self-directed English vocabulary learning with a mobile application in everyday context. Proceedings 10th World Conference on Mobile and Contextual Learning (mLearn), 24-31. Beijing Normal University. Retrieved from http://mlearn.bnu.edu.cn

Elammari, H. A. B., \& Cavus, N. (2019). Investigating the factors affecting students' smartphone purchasing behaviors in the context of mobile learning. International Journal of Emerging Technologies in Learning, 14(22), 111-121. https://doi.org/10.3991/ijet.v14i22.11748

Fageeh, A. (2013). Effects of MALL applications on vocabulary acquisition and motivation. Arab World English Journal, 4(4), 420-447. https://awej.org/images/AllIssues/Volume4/Volume4Number4Dec2013/25.pdf

Hai-Peng, H., \& Li-Jing, D. (2007). Vocabulary acquisition in multimedia environment. US-China Foreign Language, $\quad 5(8), \quad 55-59 . \quad$ Retrieved $\quad$ from https://pdfs.semanticscholar.org/be42/7afac1139058199ff41ff72e0b00ec2900f8.pdf?_ga=2.259243018.1078 22271.1594411069-62248119.1594237457

Han, T., \& Gürlüyer, M. (2017). Examining the perceptions of elementary level EFL university students regarding the use of smartphones in learning EFL vocabulary. Erzincan University Journal of Education Faculty, 19(2), 19-36. https://doi.org/10.17556/erziefd.330085

Hedge, T. (2000). Teaching and learning in the language classroom. Oxford University Press.

Heil, C. R., Wu, J. S., \& Lee, J. J. (2016). A review of mobile language learning applications: Trends, challenges, and opportunities. The EUROCALL Review, 24(2), 32-50. https://doi.org/10.4995/eurocall.2016.6402

Hossain, M., \& Ahmed, S. (2016). Academic use of smartphones by university students: A developing country perspective. The Electronic Library, 34(4), 651-665. https://doi.org/10.1108/EL-07-2015-0112

Hwang, G., \& Fu, Q. (2019). Trends in the research design and application of mobile language learning: A review of 2007-2016 publications in selected SSCI journals. Journal of Interactive Learning Environments, 27(4), 567-581. https://doi.org/10.1080/10494820.2018.1486861

Hwang, G., \& Wu, P. (2014). Applications, impacts and trends of mobile technology-enhanced learning: A review of 2008-2012 publications in selected SSCI journals. International Journal of Mobile Learning and Organisation, 8(2), 83-95. https://doi.org/10.1504/IJMLO.2014.062346

Kabooha, R., \& Elyas, T. (2015). The effects of YouTube in multimedia instruction for vocabulary learning: Perceptions of EFL students and teachers. English Language Teaching, 11(2), 72-81. https://doi.org/10.5539/elt.v11n2p72

Khabsarian-Dehkordi, F., \& Ameri-Golestan, A. (2016). Effects of mobile learning on acquisition and retention of vocabulary among Persian-speaking EFL learners. CALL_EJ, 17(2), 43-56.

Klímová, B. (2018). Mobile phones and/or smartphones and their apps for teaching English as a foreign language. Education and Information Technologies, 23(3), 1091-1099. https://doi.org/10.1007/s10639-017-9655-5

Kukulska-Hulme, A., Pettit, J., Bradley, L., Carvalho, A., Herrington, A., Kennedy, D., \& Walker, A. (2011). 
Mature Students Using Mobile Devices in Life and Learning. International Journal of Mobile and Blended Learning, 31(1), 18-52. https://doi.org/10.4018/jmbl.2011010102

Lawrence, D. (2014). Students' experiences of using SMS for vocabulary development: A case study (p. 310). Conference proceedings of ICT for language learning. Retrieved from http://www.libreriauniversitaria

Mahdi, H. S. (2018). Effectiveness of mobile devices on vocabulary learning: A meta-analysis. Journal of Educational Computing Research, 56(1), 134-154. https://doi.org/10.1177/0735633117698826

Nation, P. (1994). New ways in teaching vocabulary. TESOL.

Pilar, R., Jorge, A., \& Cristina, C. (2013). The use of current mobile learning applications in EFL. 13th International Educational Technology Conference. Social and Behavioral Sciences, 103, 1189-1196. https://doi.org/10.1016/j.sbspro.2013.10.446

Rahimi, M., \& Miri, S. S. (2014). The impact of mobile dictionary use on language learning. International Conference on Current Trends in ELT. Social and Behavioral Sciences, 98, 1469-1474. https://doi.org/10.1016/j.sbspro.2014.03.567

Sandberg, J., Maris, M., \& Geus, K. (2011). Mobile English learning: An evidence-based study with fifth graders. Computers and Education, 57(1), 1334-1347. https://doi.org/10.1016/j.compedu.2011.01.015

Steel, C. (2012). Fitting learning into life: Language students' perspectives on benefits of using mobile apps. Proceedings of ascilite 2012, Future Challenges Sustainable Future. Wellington. Retrieved from http://www.ascilite.org.au/conferences/wellington12/2012/images/custom/steel\%2c_caroline_-_fitting_lear ning.pdf

Wallace, M. J. (1989). Teaching vocabulary. ELBS Heinemann Education Books.

$\mathrm{Wu}, \mathrm{Q}$. (2014). Learning ESL vocabulary with smartphones. Procedia-Social and Behavioral Sciences, 143, 302-307. https://doi.org/10.1016/j.sbspro.2014.07.409

Yaman, I., Şenel, M., \& Yeşilel, D. (2015). Exploring the extent to which ELT students utilise smartphones for language learning purposes. South African Journal of Education, 35(4), 1-9. https://doi.org/10.15700/saje.v35n4a1198

Yang, J. (2013). Mobile assisted language learning: Review of the recent applications of emerging mobile technologies. English Language Teaching, 6(7), 19-25. https://doi.org/10.5539/elt.v6n7p19

Zhang, S. (2016). Mobile English learning: An empirical study on an APP, English Fun Dubbing. International Journal of Emerging Technologies in Learning, 11(12), 4-8. https://doi.org/10.3991/ijet.v11i12.6314

\section{Copyrights}

Copyright for this article is retained by the author, with first publication rights granted to the journal.

This is an open-access article distributed under the terms and conditions of the Creative Commons Attribution license (http://creativecommons.org/licenses/by/4.0/). 